\title{
EDITORIAL
}

\section{Directions from Contributors}

Virtually all scientific journals have a series of instructions to authors setting out the requirements of the journal which authors are expected to follow when they prepare a paper for submission. These instructions go under a variety of names, Instructions to Authors, Guidance to Authors, Directions to Contributors, etc. etc., and often apply to matters outside the preparation of the manuscript, but whatever they are called they are, in effect, requirements placed upon authors by the Editor or the Editorial Boards of the journals.

During the course of some discussions on the future of scientific publications a chance remark set me thinking: what do contributors require of scientific journals and their editors?

One way of getting some answers to this question would be to conduct a survey of the consumers, to consult the readers in some way. In one important respect scientific journals differ from most other publications in that their readers (the traditional target for consumer marketing surveys), for the most part, are actual or potential contributors. One could argue that those in charge of library budgets are the real customers for scientific journals but few librarians, nowadays, stock journals in which their readers have no interest. Thus we return to my original question: what do the contributors require of a scientific journal?

One slightly cynical colleague remarked that the essential requirements for authors were rapid acceptance and publication of every paper submitted without having to wait for and respond to editorial reports, to answer the comments from referees who seem to have read some other paper, or to carry out extra statistical analyses in response to some pernickety statistical editor.

I do believe that this is so; the acceptance and publication of each and every paper without critical peer review would effectively introduce a scientific Gresham's Law and would effectively so reduce the value of the scientific journal to the point where it would soon disappear from the library shelves. It would, incidentally, produce a severe crisis amongst appointment and promotion boards.

In my judgement, and from the comments from many authors, a critical but constructive peer review improves virtually all papers, as does careful editing. Furthermore, most papers which receive the rather uncommon 'accept now' recommendation on the paper as submitted have, I know, been through extensive critical peer review 'in house' before they reach the Editorial Office. Research papers need peer review to establish, independently, that the work is original and novel, and that the experimental work and the interpretations made from it stand up to independent review.

I would therefore argue that the first requirement from the contributors is objective, critical, and constructive review carried out fairly and as rapidly as is consistent with the attention that such a process requires.

Most journals with which I am familiar attempt to meet this requirement, so one is led to a second question: what criteria do authors use to select the journal to receive their papers? This is a question of great interest to all involved in the publication of scientific journals because it is crucial to the success of a journal which wishes to attract the best papers in its chosen field. 
I am not sure whether the impact factors of journals are seen as key criteria. I believe that many other factors are involved. Custom and practice are, I suspect, still common so that a journal often can get the reputation of being the 'house journal' for an Institute or Department. In many instances familiarity with a journal's requirements make publication more likely and more rapid than if one sent the paper to a less familiar journal.

Primarily, most authors want their papers seen and read (and cited) by their peers in their own field. This may be considered as a reason for choosing a specialized journal which, however, may have a more restricted circulation. For a nutritional journal which by definition is dealing with a subject at the interface of many disciplines, choosing a specialized journal could lead to papers with an important nutritional content not being widely read by nutritionists. The argument that the abstracting journals should overcome this problem is not wholly true because so much depends on the abstract and the key wording applied by the journal which initially published the paper. As I have said before, many authors regard preparing abstracts as a chore rather than the headlines which attract readers who will want to go on to read the full paper. Authors therefore require a Journal with a good international circulation and with a reputation for being critical in selecting the important research papers in all the areas of nutrition so that their papers will reach their direct peers and other researchers with the capacity to extrapolate from papers in other fields into their own.

I would be very interested to hear from authors, actual or potential, setting out what they see as their key requirements from the British Journal of Nutrition. Your comments will also be of great interest to the Editorial Policy Group which will be considering the future development of our publications.

D. A. T. Southgate 